\title{
O campo do teatro entre nós
}

\author{
Maria Helena Serôdio
}

Cumprindo a sua generosa agenda de pesquisa e questionamento no campo do teatro, a revista Sinais de cena oferece, neste número, investigações originais e importantes para a História do Teatro em Portugal, a par de considerações sobre a cena do presente - e não só deste lado da fronteira - quando vista e avaliada de forma reflexiva e crítica.

Na recuperação de um passado nosso - do que ou de forma negligente, ou com algum esforço inovador se fez - recordamos, pela pesquisa de Laurinda Ferreira, o pavor do incêndio do Teatro Baquet, no Porto em 1888, que deixou a claro, como sublinha a autora, a "leviandade com que era encarado o perigo a que se expunham todos os que frequentavam os espaços de apresentação de espectáculos", reportando-se às condições de insegurança de muitos dos teatros da época. Compondo a secção "Arquivo solto", o artigo evoca a localização deste teatro na malha da cidade (na Rua de Santo António, hoje Rua 31 de Janeiro) e as circunstâncias sociais em que operou o seu fundador, António Pereira "Baquet", referindo a autora as características arquitectónicas, técnicas, decorativas e de logística interna do edifício que abriu ao público em 1859 com a comédia-drama 0 segredo de uma família. A evocação do incêndio que ocorreu na noite de 20 para 21 de Março de 1888 é um relato pungente de uma tragédia que do palco se alastrou para a sala e corroeu todo o edifício, provocando mais de 100 mortos e deixando a cidade do Porto - e todo o pais - em estado de choque. Uma só valência positiva pode ser evocada: a de ter forçado uma legislação de maior rigor nas condições de segurança dos teatros em Portugal, o que, todavia, não impediu, posteriormente, outras ocorrências infelizes, embora nenhuma tenha atingido estas proporções alarmantes.

Na secção "Estudos aplicados" lemos uma outra evocação histórica do teatro em Portugal que traz até nós a preciosa descoberta - por Guilherme Filipe - de um texto que se julgava perdido e que constitui o primeiro exemplo do teatro de revista à portuguesa: Lisboa em 1850. Sendo "uma espécie de ópera cómica escrita por Francisco Palha e Latino Coelho" visando alguns dos acontecimentos daquele ano, não será de excluir, entre as razões da sua calorosa recepção e longevidade desse género de espectáculo em palcos portugueses, um eventual efeito de "terapia social", como comentava na altura um dos articulistas da Revolução de Setembro: "se temos ainda cura, só o ridículo nos pode curar". Curiosamente, também a história do texto original se prende a um trágico incêndio que deflagrou em 1921 no Teatro do Ginásio, onde estreara o espectáculo e se conservava o original, e o remeteu para um caixote de "salvados" que, durante muito tempo, ficou guardado no Conservatório sem etiqueta que referisse a presença daquela peça. E foi agora, pesquisando esse valioso "baú" - entretanto acolhido na Escola Superior de Teatro e Cinema, instituição que substituiu o Conservatório e é "herdeira" do seu espólio -, que Guilherme Filipe fez esta preciosa descoberta, potenciando, assim, uma análise critica do texto e das suas possiveis alusões à circunstância política e cultural do tempo em que subiu à cena naquele teatro que era conhecido como a "fábrica do riso" (Magalhães 2007: 9)

Uma terceira investigação, que recupera e avalia traços importantes da História do Teatro em Portugal, é trazida a esta mesma secção de "Estudos aplicados" pelo argumentário de Filipe Figueiredo em torno da fotografia de cena no nosso país. Pesquisando álbuns referentes a Eduardo Brasão no Museu Nacional do Teatro e analisando as fotografias referidas ao espectáculo A madrugada, sobre texto de Fernando Caldeira, que se estreou no Teatro Nacional D. Maria II em 1892, o investigador analisa um espólio significativo para interrogar de forma sistemática e conhecedora se, a esse propósito, podemos falar de fotografia de estúdio ou de fotografia de cena. Integrado num grupo de investigação do Centro de Estudos de Teatro da Universidade de Lisboa que criou e desenvolveu uma excelente base de dados de imagens de teatro - a OPSIS - já disponivel on line, e editou dois importantes livros (sob a direcção de Maria João Brilhante), Filipe Figueiredo expõe, de forma ponderada, uma argumentação que o leva a considerar tratar-se do "primeiro caso documentado em Portugal desta prática [de imagens produzidas dentro do teatro, directamente sobre a cena que decorre no palco]", antecipando-se mesmo, como procura demonstrar, aos primeiros exercícios desse género em França.

Uma outra modalidade de memória é ainda trazida a este número da Sinais de cena pela extensa entrevista que Miguel Falcão fez a João Mota, actual Director artístico do Teatro Nacional D. Maria II, para a secção "Na primeira pessoa". Desfiando uma invulgar história de vida, João Mota descreve o seu trajecto pelo teatro desde muito cedo, mas perspectiva o seu percurso num contexto familiar, social e político que o marcou profundamente e que, de algum modo, inspirou muitas das suas opções. A experiência do teatro radiofónico, a passagem pela companhia Amélia Rey Colaço - Robles Monteiro, as aprendizagens com Adolfo Gutkin, Natália Pais e Arquimedes Sousa Santos, mas sobretudo a estadia em Paris no Centre International de Recherche Théâtrale, sob a direcção de Peter Brook, inspiraram-no não apenas à criação da companhia Comuna - Teatro de Pesquisa (1972), mas também à preocupação com o ensino a vários niveis de escolaridade e para diferentes niveis etários. $E_{1}$ de facto, para lá da sua permanente actividade de encenador, são sobretudo as questões da 
educação pela arte que animam muito do que foi realizando no plano social, cultural e artístico.

$\mathrm{Na}$ evocação de uma cartografia teatral mais vasta, a secção "Em rede" traz a pesquisa de Eunice Tudela de Azevedo acerca de plataformas digitais onde se pode aceder a informações sobre Meyerhold e o seu papel decisivo na exuberância artística das vanguardas do início do século $X X$, de que foi um dos criadores mais inspirados.

Ainda de fora - dessa Europa mais a leste - chega-nos, através da secção "Notícias de fora", uma informação estimulante sobre muitos dos festivais de teatro, que anualmente se cumprem na Eslováquia, dando conta de uma grande diversidade de oferta e de um interesse genuino por parte do público.

E falando de festivais, vale a pena recordar que, na secção "Passos em volta", dois dos artigos percorrem momentos importantes do festival Alkantara em Lisboa e dos Festivais Gil Vicente em Guimarães. Mas cabem ainda nesta secção reflexões analíticas sobre o espectáculo do Teatro Aberto Londres, o que os Artistas Unidos criaram a partir de Feliz aniversário, de Harold Pinter, Tell Me Lies, pelo grupo 0TTO no Porto, e ainda o que o Teatro Praga e os Músicos do

'A tradução inglesa Postdramatic Theatre por Karen Jürs-Munby foi editada pela Routledge em

2006, circulando no mercado lusófono, em

tradução de Pedro

Sussekind, Teatro pósdramático, publicado pela

editora paulista Cosac

Naify, em 2007

${ }^{2}$ A edição francesa de

L'avenir du dram

Écritures dramatiques

contemporaines (Éditions

Circé, 1999) teve tradução

portuguesa, da autoria de

Alexandra Moreira da

Silva, em 2002, pel

Campo das Letras. Foram

entretanto publicados

alguns outros textos do autor em 0 outro diálogo:

Elementos para uma

poética do drama

modernoe

contemporâneo, com

tradução de Luis Varela (Editora Licorne, 2011)

já em 2012, saiu nas

edições Seuil, a sua obra mais recente: Poétique du

drame moderne: D

Henrik Ibsen à Bernard-

Marie Koltès.
Tejo estrearam no CCB festejando Shakespeare e Purcell a propósito de Sonho de uma noite de Verão.

É ainda em torno de espectáculos concretos, que Sebastiana Fadda, partindo embora das traduções de peças de Eduardo de Filippo - recentemente editadas nos livrinhos de teatro pelos Artistas Unidos -, nos traz uma visão abrangente e de grande fulgor interpretativo do teatro deste extraordinário autor / actor, abrindo assim a secção "Leituras" deste número da Sinais de cena. Na mesma secção lemos ainda uma anotação interessante de Rui Pina Coelho em torno do Teatro do Vestido e uma reflexão de Ana Campos a propósito da transversalidade dos estudos que encontramos no volume que Gabriela Borges organizou para uma edição conjunta da Gradiva e do Centro de Investigação em Artes e Comunicação da Universidade do Algarve.

De um outro lado do país - do seu interior, o Fundão - chega-nos uma expressiva documentação fotográfica sobre o trabalho que Nuno Pino Custódio - com saber, inspiração e persistência - tem vindo a desenvolver com a máscara e a agilização do trabalho do actor sob inspiração da commedia dell'arte na sua Estação Teatral, ocupando aqu a secção "Portefólio" e dando conta de um percurso singular já com raízes locais e visibilidade dentro e fora do país.

Uma outra discussão vasta e candente entra ainda neste número da revista através do seu "Dossiê temático", que resulta de uma selecção de comunicações apresentadas a um colóquio promovido pelo Centro de Estudos de Teatro da Faculdade de Letras da Universidade de Lisboa em conjugação com um projecto europeu de teatro - Prospero - em que se empenhou o Centro Cultural de Belém, através do seu anterior Director - António Mega Ferreira - e da sua entusiástica e competentíssima assessora Gabriela Cerqueira. Com a presença, entre outros, de Christine Zurbach, professora da Universidade de Évora, de Didier Plassard, professor da Universidade Paul Valery Monpelier 3, de Carole Guidicelli, investigadora do Instituto
Internacional da Marioneta, e da jovem investigadora Maria Carneiro, discutiu-se o teatro contemporâneo na sua formulação contraditória "Entre a desdramatização e a redramatização", invocando naturalmente o conceito enunciado em 1999 por Hans-Thies Lehmann, que tem sido, entretanto, discutido, apreciado, contestado e reformulado por outros teóricos, de entre os quais se destacam, na sua argumentação mais judiciosa, os trabalhos teóricos e críticos de Jean-Pierre Sarrazac, como, entre outros, 0 futuro do drama ${ }^{2}$. Se em dois dos textos - o de Carole Guidicelli e Maria Carneiro - encontramos a referência concreta a criadores que podemos reportar aos conceitos em debate, Christine Zurbach e Didier Plassard promovem sobretudo uma argumentação mais radical e apaixonante em torno de alguns dos equívocos e simplificações que o conceito entretanto desencadeou.

A apresentação breve, que aqui desenho, deverá ainda sinalizar quer o estudo da dimensão trágica da peça de Bernardo Santareno O judeu (pela escrita de Elsa Rita dos Santos na secção "Estudos aplicados"), quer a reflexão para a mesma secção - de Marisa Falcón sobre uma "estratégia de sobrevivência" que a comunidade teatral portuguesa terá necessariamente de adoptar para fazer face à redução aflitiva do financiamento ao teatro em Portugal. Não é difícil anotar a convergência destes dois tópicos que, desgraçadamente, embora reportados a tempos e modalidades de actuação diferentes, não deixam de localizar entre nós uma situação trágica de asfixia que pouco tem a ver com o valor da arte e dos artistas de teatro, antes aponta para uma endémica dificuldade de afirmar projectos de valor ou de ver reconhecida a importância da arte na vida cultural portuguesa.

Agradecendo aos autores a sua estimulante participação neste número da Sinais de cena, não podemos deixar de sublinhar também a generosa disponibilização de fotografias, livros e informação relevante por parte de muitas companhias, do Museu Nacional do Teatro, da Escola Superior de Teatro e Cinema e de pessoas singulares a quem os fazedores desta revista muito ficam a dever. Um reconhecimento muito especial é ainda devido ao Teatro Nacional S. João e ao Teatro Nacional D. Maria II que, de há muito - com a publicidade que aqui disponibilizam - acompanham este nosso esforço de declarar que o teatro em Portugal existe, ainda que limitado por constrangimentos financeiros, e dele é preciso falar: analisando-o, seguindo o seu percurso, interpelando os seus sentidos e assinalando o seu valor cultural e artístico.

\section{Referências bibliográficas}

BRILHANTE, Maria João /MAGALHÃES, Paula / FIGUEIREDO, Filipe (orgs.) (2011), Imagens de uma ausência: Modos de (re)conhecimento do teatro através da imagem, Lisboa, Edições Colibri.

_- (2011b), Teatro e imagens, Lisboa, Edições Colibri.

MAGALHÃES, Paula (2007), Os dias alegres do Ginásio: Memórias de um teatro de comédia. Lisboa, dissertação de mestrado em Estudos de Teatro, apresentada à Faculdade de Letras da Universidade de Lisboa (texto policopiado). 